\title{
Genetic Risk Factors and the Anti-Atherosclerotic Effect of Pioglitazone on Carotid Atherosclerosis of Subjects with Type 2 Diabetes-A Retrospective Study-
}

\author{
Miyoko Saitou ${ }^{1}$, Takeshi Osonoi ${ }^{1}$, Ryuzo Kawamori ${ }^{2}$, Naoto Katakami ${ }^{3}$, Hideaki Kaneto $^{3}$, \\ Munehide Matsuhisa ${ }^{3}$, and Yoshimistu Yamasaki ${ }^{3}$ \\ ${ }^{1}$ Naka Kinen Clinics, Japan \\ ${ }^{2}$ Department of Medicine, Metabolism and Endocrinology, Juntendo University School of Medicine, Japan \\ ${ }^{3}$ Department of Internal Medicine and Therapeutics, Osaka University Graduate School of Medicine, Osaka, Japan
}

\begin{abstract}
Aim: Pioglitazone, an agonist of peroxisome proliferator-activated receptor $\gamma$, showed various antiatherosclerotic effects on type 2 diabetic patients. This retrospective study was done to ascertain which risk factor(s) associate with anti-atherosclerotic effects of pioglitazone.

Methods: We enrolled 160 diabetic patients treated through diet only and 62 treated with pioglitazone and annually evaluated carotid maximum (MaxIMT) and averaged intima-media thickness (AveIMT) for 2 years. We analyzed the relation of 99 single-nucleotide polymorphisms (SNP) as well as conventional risk factors with the progression or regression of carotid atherosclerosis.

Results: The D allele of the angiotensin-converting enzyme (ACE) gene and 677 allele of the methyllene-tetrahydrofolate reductase (MTHFR) gene showed a significant association with increases in MaxIMT among the diabetic subjects treated through diet only. The pioglitazone-treated carriers of the $\mathrm{D}$ allele showed an attenuation of MaxIMT as compared with the diet-treated carriers. The pioglitazone-treated carriers of the $677 \mathrm{~T}$ allele carriers showed a significant attenuation of MaxIMT compared with the diet-treated carriers.

Conclusions: Pioglitazone may exert anti-atherosclerotic effects on type 2 diabetics carrying the ACE gene's D allele and/or MTHFR gene's 677T allele, who showed a progression of carotid atherosclerosis without the drug.
\end{abstract}

J Atheroscler Thromb, 2010; 17:386-394.

Key words; Pioglitazone, IMT, Single nucleotide polymorphism, Atherosclerosis

\section{Introduction}

Subjects with type 2 diabetes are at high risk of developing cardiovascular diseases ${ }^{1)}$. Haffner et al. reported the risk of a cardiovascular event in patients with diabetes to be similar to that in non-diabetic patients with a history of myocardial infarction ${ }^{2)}$. We have shown that age, diabetes, dyslipidemia, hypertension, and smoking are associated with an increase in

Address for correspondence: Yoshimitsu Yamasaki, Department of Internal Medicine and Therapeutics, Osaka University Graduate School of Medicine, 2-2 Yamadaoka, Suita City, Osaka 565-0871, Japan

E-mail: yamasaki@medone.med.osaka-u.ac.jp

Received: June 16, 2009

Accepted for publication: October 13, 2009 carotid intima-media thickness (IMT), a surrogate endpoint of cardiovascular events, in subjects with type 2 diabetes ${ }^{3)}$. Furthermore, we recently identified 7 out of 106 single nucleotide polymorphisms (SNPs) to be associated with advanced carotid IMT in subjects with type 2 diabetes ${ }^{4)}$.

Thiazolidinediones, agonists of peroxisome proliferator-activated receptor $\gamma$, have been shown to have beneficial effects on lipid profiles, inflammation, coagulation, and endothelial cell function in humans ${ }^{5-77}$. Furthermore, pioglitazone, a thiazolidinedione, slowed the increase in carotid IMT among subjects with type 2 diabetes $^{8-10)}$. Recent studies have shown that longterm administration of pioglitazone significantly reduces the frequency of cardiovascular events in highrisk patients with type 2 diabetes ${ }^{11-13)}$. Pioglitazone 
therefore has athero-protective potential. However, the mechanism by which it exerts athero-protective effects in vivo remains unclear. The aim of this study was to clarify which risk factor(s) including various SNPs are associated with the reduction of carotid atherosclerosis in patients with type 2 diabetes treated with pioglitazone.

\section{Materials and Methods}

\section{Subjects}

Type 2 diabetic subjects aged 30-80 years, who had visited the outpatient facility of Naka Kinen Clinics for more than two years and were treated either through diet only or with pioglitazone for hyperglycemic control, were enrolled in this study from Jan. 15 2007 through June 15, 2007. Subjects with renal dysfunction (serum creatinine $\geq 1.5 \mathrm{mg} / \mathrm{dL}$ ), liver dysfunction, or chronic cardiac failure were excluded. A total of 222 subjects (160 treated through diet only and 62 treated with pioglitazone) were included. The treatment regimens for diabetes had been randomly assigned and were not changed during the observation period. The determination of type 2 diabetes was based on World Health Organization criteria. The study protocol was approved by the committee on the ethics of human research of Juntendo University School of Medicine. Informed consent was obtained from all of the enrolled subjects.

\section{Meacurement of Carotid Atherosclerosis}

A series of ultrasonographic scannings of the carotid artery were performed using an echotomographic system (SDU 2200, Shimazdu Medical Inc., Japan) with an electrical linear transducer (midfrequency of 7.5 MHz). The resolution limit of this system using $7.5 \mathrm{MHz}$ was approximately $0.1 \mathrm{~mm}$. Conventional B-mode imaging of the extracranial common carotid artery, the carotid bulb, and the internal carotid artery in the neck was performed bilaterally from three different longitudinal projections (i.e., anterior-oblique, lateral, and posterior-oblique) as well as the transverse projection, as reported ${ }^{3,14)}$. Carotid intima-media thickness (IMT) was measured as the distance from the leading edge of the first echogenic line to the leading edge of the second echogenic line ${ }^{15)}$. Three determinations of IMT were made at the site of greatest thickness (MaxIMT) and $1 \mathrm{~cm}$ upstream and $1 \mathrm{~cm}$ downstream from the site of greatest thickness. These three values were averaged. The greatest of the six averaged IMT values (three from the left and three from the right) was used as representative (AveIMT) for each individual. Physicians con- ducted all scans. Computer software (Intima-scope, Media Cross Inc., Tokyo, Japan, USA Pat. I03-3358$3362 / \mathrm{JM}$ ) was used for the determination of IMT. The physicians were unaware of the clinical characteristics of the subjects. The mean difference in IMT between two observers was $0.06 \mathrm{~mm}$ and the standard deviation was $0.04 \mathrm{~mm}$. The mean difference in IMT between two determinations was $0.01 \mathrm{~mm}$ and the standard deviation was $0.04 \mathrm{~mm}$, demonstrating good reproducibility of repeated measurements.

\section{Assessment of Other Parameters}

Blood was withdrawn for analyses of serum total cholesterol, serum HDL-cholesterol (HDL), serum triglyceride, LDL-cholesterol (LDL) and HbA1c levels by standard laboratory techniques. Blood pressure and body mass indexes (BMI) were also measured.

\section{Selection of SNPs}

With the use of PubMed, we selected 99 candidate gene SNPs that are potentially associated with atherosclerosis, diabetes mellitus, hypertension or dyslipidemia (Appendix).

\section{Genotyping of SNPs}

Venous blood was collected from each subject and genomic DNA was isolated with a DNA isolation kit (Qiagen). The genotypes of the 99 SNPs of each subject were determined with a fluorescence- or colorimetry-based allele-specific DNA-primer probe assay system (Toyobo Gene Analysis) as described in detail by Yamada et al. ${ }^{16)}$.

\section{Statistical Analysis}

Data are expressed as the mean \pm SEM and all statistical tests were two-sided. A one-way ANOVA was used to compare the parameters of subjects and a paired $t$-test was used to evaluate the significance of changes in values during the observation period.

\section{Results}

Patient characteristics at baseline, changes in AveIMT and MaxIMT during the observation period, and the univariate coefficient correlations ( $\mathrm{rr}$ ) are shown in Table 1. For all parameters (age, gender, BMI, hemoglobin A1c levels, lipid profiles, and blood pressure levels), there was no significant difference at baseline between the subjects treated through diet only and those on pioglitazone. AveIMT (0.810 \pm 0.013 and $0.828 \pm 0.018 \mathrm{~mm})$ and MaxIMT $(0.979 \pm$ 0.018 and $1.012 \pm 0.024 \mathrm{~mm})$ at baseline did not differ significantly between those treated through diet 
Table 1. Patients' characteristics and univariate correlations of annual changes in AveIMT and MaxIMT with clinical parameters at baseline

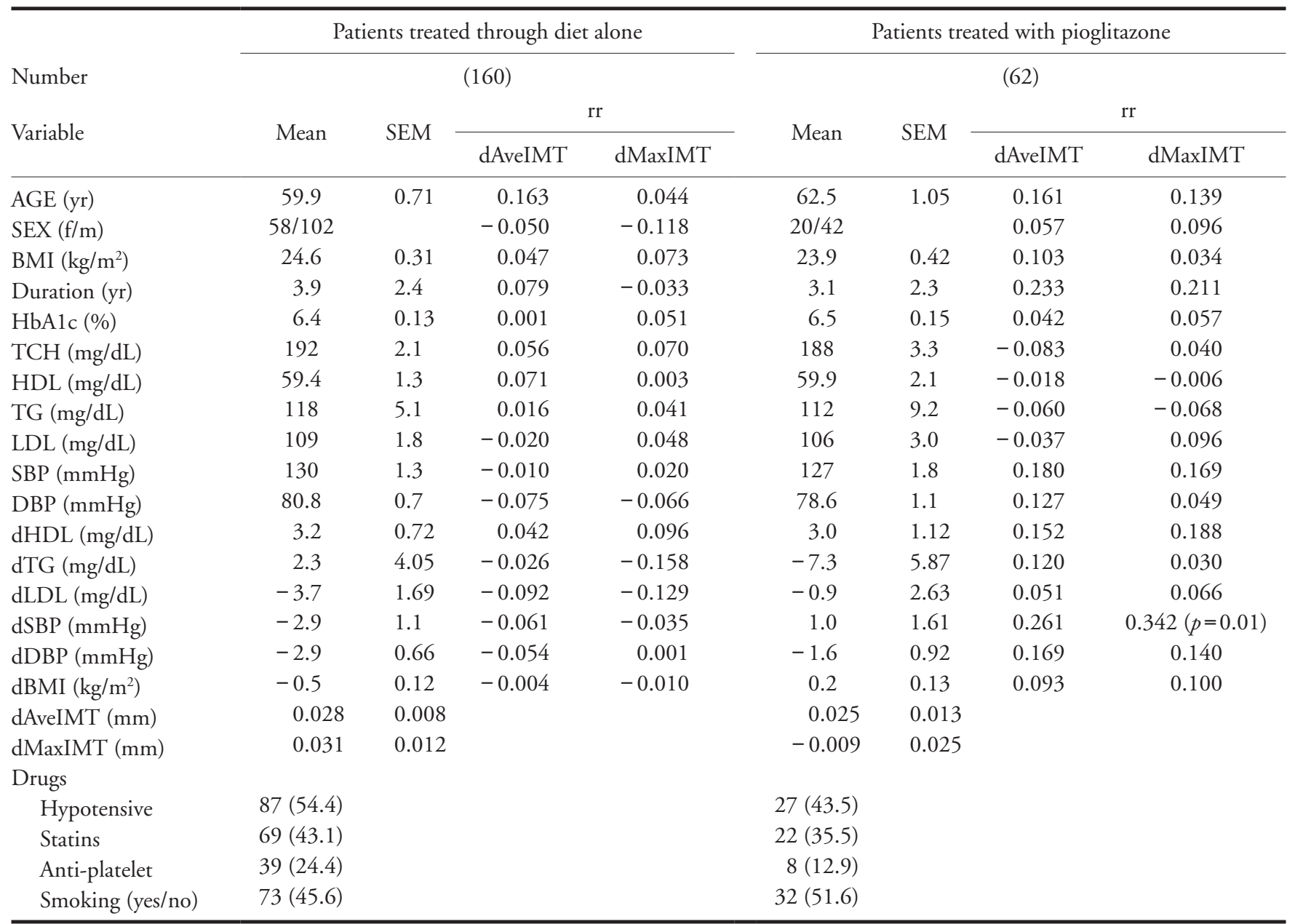

Data are shown as the number $(\%)$ or mean \pm SE.

BMI; body mass index, HbA1c; hemoglobin A1c, dHbA1c; annual change in hemoglobin A1c, TCH; total cholesterol, HDL; high-density lipoprotein cholesterol, TG; triglycemia, LDL; low-density lipoprotein cholesterol, SBP; systolic blood pressure, DBP; diastolic blood pressure, dHDL; change in HDL, dTG; change in TG, dLDL; change in LDL, dSBP; change in SBP, dDBP; change in DBP, dBMI; change in BMI, dAveIMT; change in AveIMT, dMaxIMT; change in MaxIMT

rr: univariate coefficient correlation

Smoking includes current or past (more than 200 cigarettes/day x years) smoking.

only and those given pioglitazone, either.

During the observation period, hemoglobin A1c levels decreased significantly from $6.44 \pm 0.13$ to 6.12 $\pm 0.07 \%$ in the subjects treated through diet only and from $6.52 \pm 0.18$ to $6.12 \pm 0.05 \%$ in those treated with pioglitazone. Diabetic subjects treated with pioglitazone or through diet only showed variations in change of AveIMT $(0.025 \pm 0.013$ vs $0.028 \pm 0.008$ $\mathrm{mm}$, respectively) and MaxIMT $(-0.009 \pm 0.025$ vs $0.031 \pm 0.012 \mathrm{~mm}$, respectively). There was no significant difference in changes of AveIMT or MaxIMT between the two groups. There was no significant correlation between variables (age, gender, BMI, hemo- globin A1c levels, lipid profiles, and blood pressure levels) at baseline and changes in AveIMT or MaxIMT of subjects treated with or without pioglitazone (Table 1). Hypotensive drugs, statins, anti-platelet drugs, and smoking did not significantly affect changes in AveIMT and MaxIMT in the diabetic patients.

Out of the 99 SNPs evaluated, the ACE gene I/D polymorphism and the MTHFR gene C677T polymorphism were found to be associated with increases or reductions in AveIMT and MaxIMT in diabetic patients treated with or without pioglitazone. Among carriers of the ACE D allele (ID plus DD genotypes), AveIMT and MaxIMT in the diabetic 
patients treated through diet alone $(n=93)$ increased significantly (from $0.802 \pm 0.017$ to $0.831 \pm 0.017 \mathrm{~mm}$, $p=0.0055$ and from $0.969 \pm 0.023$ to $0.998 \pm 0.021$ $\mathrm{mm}, p=0.05)$, while those in the pioglitazone-treated group $(n=32)$ showed no significant change (from $0.860 \pm 0.026$ to $0.859 \pm 0.025 \mathrm{~mm}$ and from $1.050 \pm$ 0.037 to $0.993 \pm 0.048 \mathrm{~mm})$. The increase in MaxIMT was attenuated in the pioglitazone-treated group as compared with diet-treated group $(-0.055 \pm 0.040$ vs $0.032 \pm 0.015 \mathrm{~mm}, p=0.0119)$. Similarly, the increase of AveIMT was attenuated in the pioglitazone-treated group $(0.003 \pm 0.019$ vs $0.031 \pm 0.010 \mathrm{~mm})$ but not significantly. On the other hand, among subjects with the ACE II genotype, AveIMT increased significantly in both the pioglitazone-treated group $(n=30)$ and the diet-treated group $(n=67)$ and there was no significant difference in the changes of AveIMT between the two. Similarly, there was no significant difference in the changes of MaxIMT between the groups (Fig. 1). These results suggest that pioglitazone-treatment did not significantly affect changes in AveIMT and MaxIMT among diabetic patients with the ACE II genotype. Hemoglobin A1c levels were consistently reduced irrespective of the ACE I/D genotype during the observation period.

In the diabetic patients treated through diet alone $(n=116)$, the subjects with MTHFR C677T genotypes (CC, CT, TT) showed a trend fowards increased AveIMT $(0.012 \pm 0.022,0.031 \pm 0.011,0.042 \pm 0.017$ $\mathrm{mm}$, respectively, $p=0.377)$ and MaxIMT $(-0.003$ $\pm 0.034,0.031 \pm 0.016,0.071 \pm 0.030 \mathrm{~mm}$, respectively, $p=0.099)$ and the MTHFR 677T allele carriers (677CT and 677TT genotypes, $n=116$ ) showed significantly increased AveIMT (from $0.804 \pm 0.012$ to $0.839 \pm 0.013 \mathrm{~mm}, p=0.0010$ ) and MaxIMT (from $0.971 \pm 0.016$ to $1.010 \pm 0.018 \mathrm{~mm}, p=0.0069)$ during the observation period. However, in the carriers of the MTHFR 677T allele treated with pioglitazone $(n=44)$, there was no significant change in AveIMT and MaxIMT (from $0.843 \pm 0.022$ to $0.862 \pm 0.022$ $\mathrm{mm}$ and from $1.040 \pm 0.031$ to $1.010 \pm 0.040 \mathrm{~mm}$, respectively). The increase in MaxIMT was significantly attenuated in the pioglitazone-treated group as compared with the diet-treated group $(-0.021 \pm 0.033$ vs $0.044 \pm 0.014 \mathrm{~mm}, p=0.0383$ ), while there was no significant difference in the changes of IMT between the two groups. On the other hand, in subjects with the MTHFR 677CC genotype, AveIMT and MaxIMT did not differ significantly before versus after the observation period in the pioglitazone-treated group $(n=18)$ or diet-treated group $(n=44)$. Also, there was no significant difference in the changes of IMT between the two groups (Fig. 2). Hemoglobin A1c levels were consistently reduced during the observation period irrespective of MTHFR $677 \mathrm{C} / \mathrm{T}$ genotype.

These results suggest that pioglitazone treatment attenuates the progression of carotid atherosclerosis in type 2 diabetic subjects with the ACE D allele and the MTHFR 677T allele.

\section{Discussion}

Cross-sectional studies have shown that several risk factors including aging, lipid profiles, blood glucose levels and blood pressure levels contribute to the increase in carotid artery IMT in subjects with type 2 diabetes $^{3,17)}$ and act as surrogate markers of cardiovascular disease ${ }^{18-20)}$. In addition, many genetic risk factors have been found to associate with cardiovascular disease $^{21)}$ and advanced IMT ${ }^{22-26)}$. Recently, several studies showed that antidiabetic drugs attenuated the increase in carotid IMT in diabetic patients ${ }^{27,28)}$. Among the antidiabetic drugs, pioglitazone, a thiazolidinedione, retarded carotid atherosclerosis in subjects with type 2 diabetes in both short-term and long-term trials ${ }^{8-10)}$. Furthermore, the treatment with pioglitazone of high-risk subjects with type 2 diabetes significantly reduced the frequency of coronary vascular events $^{11-13)}$. However, it remained unknown as to which risk factor influences the effectiveness of pioglitazone against the development of atherosclerosis. To answer this question, have carotid IMT was evaluated long term in subjects with type 2 diabetes treated with pioglitazone or without antidiabetic drugs. The association of risk factors including genetic risks with the change in carotid IMT was assessed.

Diabetic subjects treated with or without pioglitazone showed no significant differences in age, gender, BMI, hemoglobin A1c levels, lipid profiles, and blood pressure levels at baseline. These values at baseline did not show any significant univariate correlation with the change in AveIMT or MaxIMT of subjects with type 2 diabetes treated with or without pioglitazone (Table 1). Therefore, age, gender, BMI, hemoglobin A1c levels, lipid profiles, and blood pressure levels at baseline do not serve as a marker of the effectiveness of pioglitazone against the development of atherosclerosis in type 2 diabetic subjects.

In this study, pioglitazone-treated subjects carrying the ACE D allele showed an attenuation of MaxIMT and AveIMT compared with diet-treated subjects having the ACE D allele. Previous cross-sectional studies demonstrated that the ACE D allele was a genetic risk factor for carotid atherosclerosis ${ }^{23}, 25$ ). It has been shown that the ACE gene is expressed in endothelial cells and smooth muscle cells. In addition, 

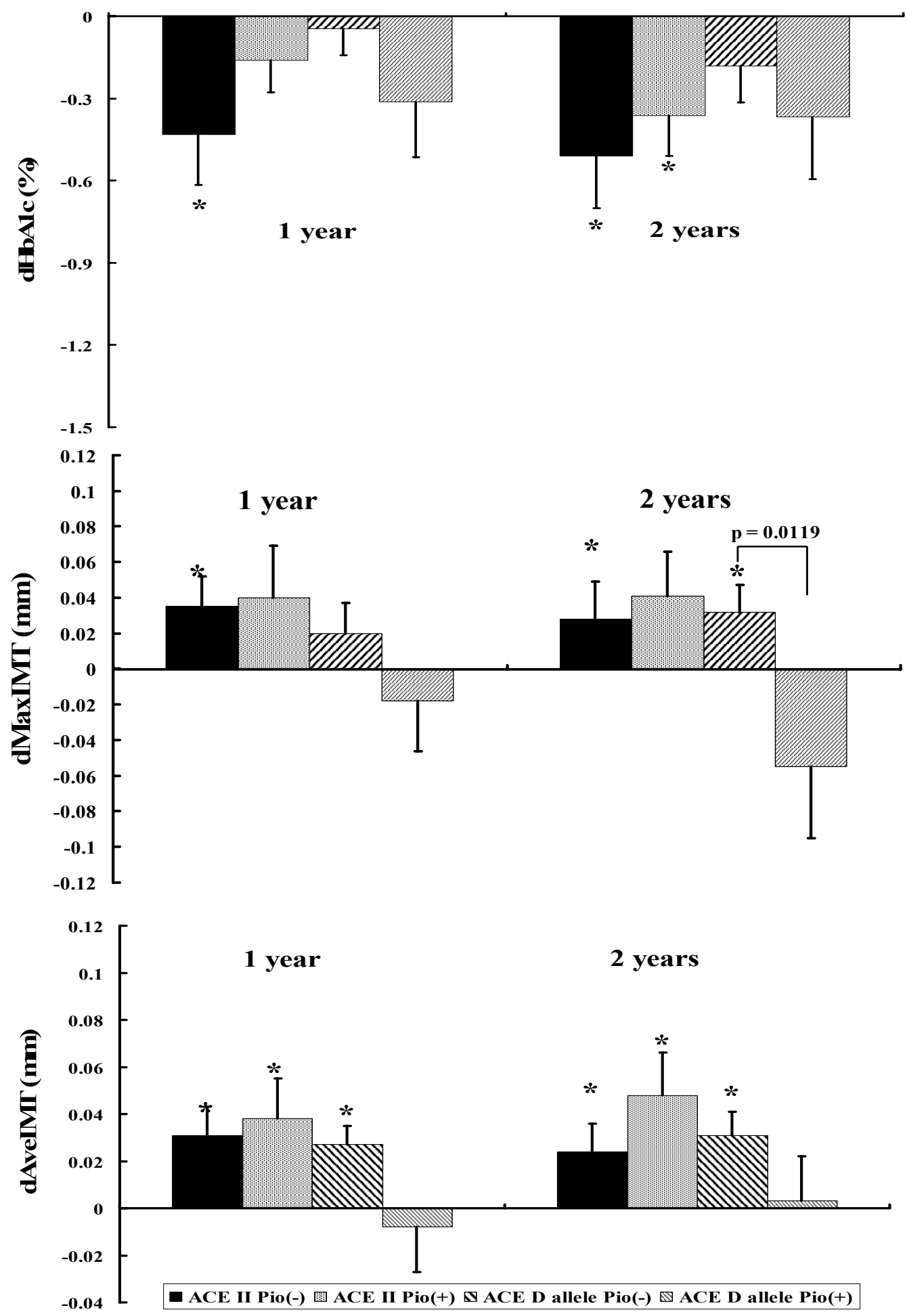

Fig. 1. Changes in hemoglobin A1c levels (dHbA1c: top panel), MaxIMT (dMaxIMT: middle panel), and AveIMT (dAveIMT: bottom panel) from baseline at one year and two years.

Black bar, subjects treated through diet only having the ACE gene II genotype (ACE II Pio(-), subjects treated with pioglitazone having the ACE gene II genotype (ACE II Pio $(+)$ ), subjects treated through diet only having the D allale of the ACE gene (ACE D allele Pio(-)), and subjects treated with pioglitazone having the D allale of the ACE gene (ACE D allele Pio $(+)$ ). An asterisk indicates a significant difference compared with the baseline value in the paired $t$-test. 


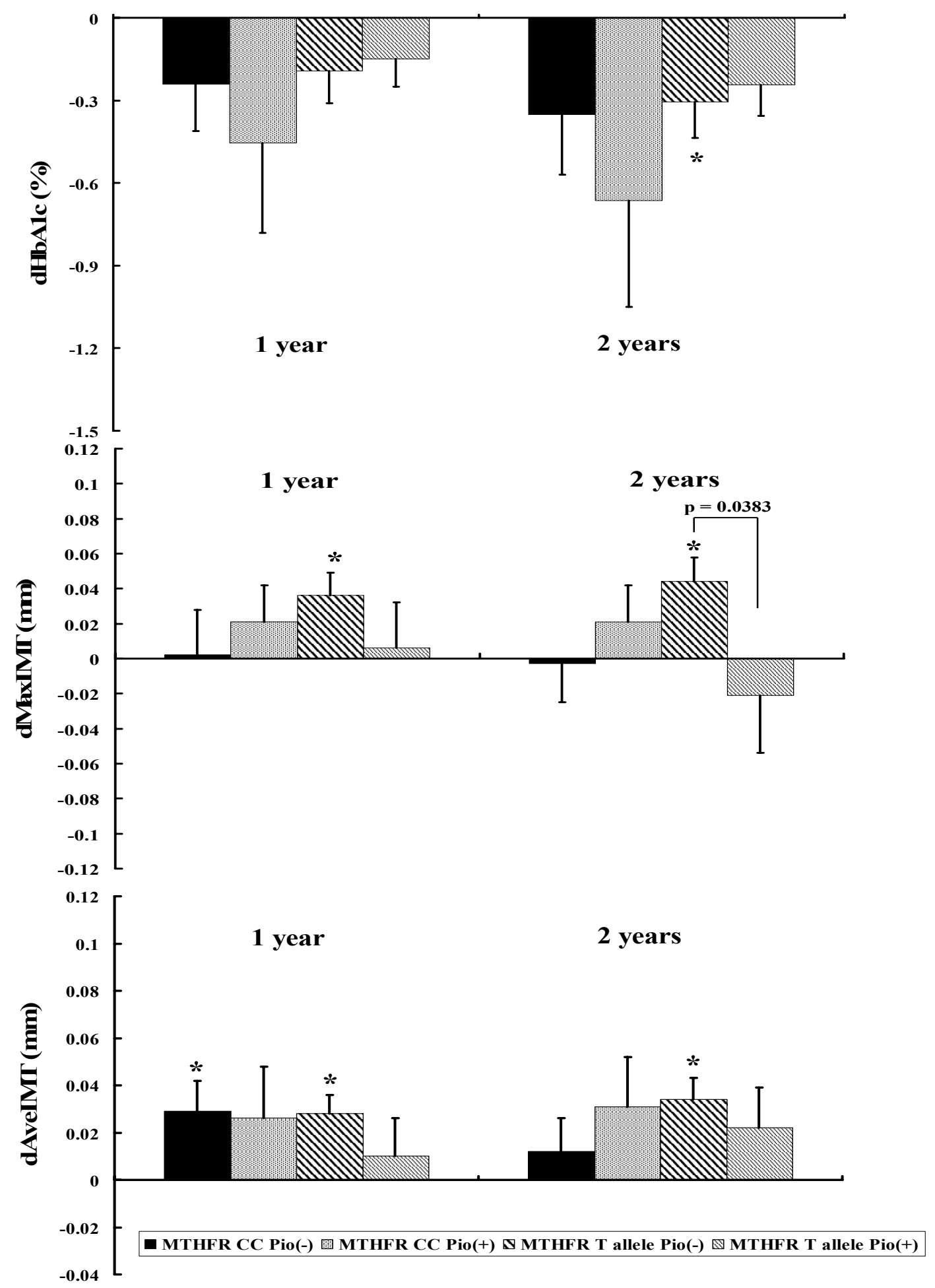

Fig. 2. Changes in hemoglobin A1c levels (dHbA1c: top panel), MaxIMT (dMaxIMT: middle panel), and AveIMT (dAveIMT: bottom panel) from baseline at one year and two years.

Black bar, subjects treated through diet only having the MTHFR gene 677CC genotype (MTHFR CC Pio(-)), subjects treated with pioglitazone having the MTHFR gene 677CC genotype (MTHFR CC Pio(+)), subjects treated through diet only carrying the 677T allele of the MTHFR gene (MTHFR T allele Pio(-)), and subjects treated with pioglitazone carrying the $677 \mathrm{~T}$ allele of the MTHFR gene (MTHFR T allele Pio $(+)$ ). An asterisk indicates a significant difference compared with the baseline value in the paired $t$-test. 
one study found the ACE activity in blood to be related with the ACE I/D genotype, partially due to an increased rate of transcription of the ACE D allele ${ }^{29)}$. Recently, Toba et al. reported that pioglitazone exerted anti-oxidative and anti-inflammatory effects through the inhibition of ACE expression in the aorta of rats with streptozotocin-induced diabetes ${ }^{30)}$. Together with increased expression of the ACE gene and increased renin-angiotensin system (RAS)induced oxidative stress, pioglitazone may modulate oxidative stress-induced progression of atherosclerosis by acting on the augmented RAS system in subjects with type 2 diabetes. However, the precise mechanism by which pioglitazone induces the attenuation of carotid IMT in diabetic subjects remains to be elucidated.

Hyperhomocysteinemia is proposed to promote cardiovascular disease through the induction of oxidative stress, endoplasmic reticulum stress, and proinflammatory factors ${ }^{31)}$. MTHFR is an enzyme involved in the remethylation of homocysteine to methionine ${ }^{32,33)}$. The MTHFR 677T allele results in a reduction of MTHFR activity and an increase in serum homocysteine levels in a dose-dependent manner, and thus is possibly involved in the progression of atherosclerosis ${ }^{27,34)}$. Consistent with a previous report on ischemic stroke (Cronin et al.), the present study has shown that subjects with MTHFR C677T genotypes (CC, CT, TT) tended to show an increase in IMT under pioglitazone-free conditions and that MTHFR 677T allele carriers showed significantly greater IMT as compared to non-carriers, in pioglitazone-free conditions. On the contrary, treatment with pioglitazone was found to attenuate the increase in MaxIMT in diabetic subjects with the MTHFR $677 \mathrm{~T}$ allele. The precise mechanism by which pioglitazone exerts its anti-atherosclerotic effects on diabetic subjects with this atherosclerotic genetic risk factor remains to be elucidated. However, since thiazolidinediones have been shown to modulate the expression of genes involved in pro-inflammation, cell proliferation and oxidative stress ${ }^{35,36)}$, it is possible that pioglitazone treatment attenuates the MTHFR 677T alleleinduced atherosclerosis through such a mechanism.

The ACE D allele and the MTHFR 677T allele are common in Japanese (56\% and $72 \%$, respectively) as well as in Caucasian diabetics. Our study showed that treatment with pioglitazone attenuates the progression of carotid atherosclerosis in the majority of diabetic patients who possess the ACE D or MTHFR 677T allele, who are thought to be predisposed to atherosclerosis upon treatment through diet only.

In conclusion, long-term pioglitazone-treated dia- betic subjects with the ACE D allele or the MTHFR $677 \mathrm{~T}$ allele showed an attenuation of carotid IMT as a surrogate marker of cardiovascular diseases compared with diet-treated diabetic subjects with these alleles. These results are consisted with the idea that pioglitazone exerts an anti-atherosclerotic effect especially on diabetic subjects possessing atherogenic genetic risk factors, such as the angiotensin-converting enzyme D allele and the methylene-tetrahydrofolate reductase 677T allele.

\section{References}

1) Chait A, Bierman EL: Pathogenesis of macrovascular disease in diabetesIn: Joslin's Diabetes Mellitused by Kahn CR, GCWeir GC, p648-664, Lea \& Febiger, Philadelphia, 1994

2) Haffner SM, Lehto S, Rönnemaa T, Pyörälä K, Laakso M: Mortality from coronary heart disease in subjects with type 2 diabetes and in nondiabetic subjects with and without prior myocardial infarction. N Engl J Med, 1998; 339: 229-234

3) Yamasaki $Y$, Kawamori R, Matsushima $H$, Nishizawa $H$, Kodama M, Kajimoto Y, Morishima T, Kamada T: Atherosclerosis in carotid artery of young IDDM patients monitored by ultrasound high-resolution B-mode imaging. Diabetes, 1994; 43: 634-639

4) Yamasaki Y, Katakami N, Sakamoto K, Kaneto H, Matsuhisa M, Sato H, Hori M, Haneda M, Kashiwagi A, Tanaka Y, Kawamori R, Kuno S: Combination of multiple genetic risk factors is synergistically associated with carotid atherosclerosis in Japanese subjects with type 2 diabetes. Diabetes Care, 2006; 29: 2445-2451

5) Goldberg RB, Kendall DM, Deeg MA, Buse JB, Zagar AJ, Pinaire JA, Tan MH, Kahn MA, Perez AT, Jacober SJ, GLAI Study Investigators: A comparison of lipid and glycemic effects of pioglitazone and rosiglitazone in patients with type 2 diabetes and dyslipidemia. Diabetes Care, 2005; 28: 1547-1554

6) Haffner SM, Greenberg AS, Weston WM, Chen H, Williams K, Freed MI: Effect of rosiglitazone treatment on nontraditional markers of cardiovascular disease in patients with type 2 diabetes mellitus. Circulation, 2002; 106: 679-684

7) Szapary PO, Bloedon LT, Samaha FF, Duffy D, Wolfe ML, Soffer D, Reilly MP, Chittams J, Rader DJ: Effects of pioglitazone on lipoproteins, inflammatory markers, and adipokines in nondiabetic patients with metabolic syndrome. Arterioscler Thromb Vasc Biol, 2006; 26: 182188

8) Koshiyama H, Shimono D, Kuwamura N, Minamikawa J, Nakamura Y: Rapid communication: inhibitory effect of pioglitazone on carotid arterial wall thickness in type 2 diabetes. J Clin Endocrinol Metab, 2001; 86: 3452-3456

9) Langenfeld MR, Forst T, Hohberg C, Kann P, Lubben G, Konrad T, Fullert SD, Sachara C, futzner AP: Pioglitazone decreases carotid intima-media thickness independently of glycemic control in patients with type 2 diabetes melli- 
tus: results from a controlled randomized study. Circulation, 2005; 111: 2525-2531

10) Mazzone T, Meyer PM, Feinstein SB, Davidson MH, Kondos GT, D'Agostino Sr. RB, Perez A, Provost JC, Haffner SM: Effect of pioglitazone compared with glimepiride on carotid intima-media thickness in type 2 diabetes: a randomized trial. JAMA, 2006; 296: 2572-2581

11) Dormandy JA, Charbonnel B, Eckland DJ, Erdmann E, Massi-Benedetti M, Moules IK, Skene AM, Tan MH, Lefebvre PJ, Murray GD, Standl E, Wilcox RG, Wilhelmsen L, Betteridge J, Birkeland K, Golay A, Heine RJ, Koranyi L, Laakso M, Mokan M, Norkus A, Pirags V, Podar T, Scheen A, Scherbaum W, Schernthaner G, Schmitz O, Skrha J, Smith U, Taton J, PROactive investigators: Secondary prevention of macrovascular events in patients with type 2 diabetes in the PROactive Study:, PROspective pioglitAzone Clinical Trial In macroVascularEvents; :a randomised controlled trial. Lancet, 2005; 366: 1279-1289

12) Wilcox R, Bousser MG, Betteridge DJ, Schernthaner G, Pirags V, Kupfer S, Dormandy JA; PROactive InvestigatorsEffects of pioglitazone in patients with type 2 diabetes with or without previous stroke: results from PROactive:, PROspective pioglitAzone Clinical Trial In macroVascular Events 04. Stroke, 2007; 38: 865-873

13) Erdmann E, Dormandy JA, Charbonnel B, Massi-Benedetti M, Moules IK, Skene AM; PROactive Investigators: The effect of pioglitazone on recurrent myocardial infarction in 2,445 patients with type 2 diabetes and previous myocardial infarction: results from the PROactive:, PROactive 05; Study. J Am Coll Cardiol, 2007; 49: 1772-1780

14) Kawamori R, Yamasaki $Y$, Matsushima $H$, Nishizawa $H$, Nao K, Hougaku H, Maeda H, Handa N, Matsumoto M, Kamada T: Prevalence of carotid atherosclerosis in diabetic patients Ultrasound high-resolution B-mode imaging on carotid arteries. Diabetes Care, 1992; 15: 12901294

15) Pignoli P, Tremoli E, Poli A, Oreste P, Paoletti R: Intimal plus medial thickness of the arterial wallA direct measurement with ultrasound imaging. Circulation, 1986; 74: 1399-1406

16) Yamada $Y$, Izawa $H$, Ichihara $S$, Takatsu $F$, Ishihara $H$, Hirayama H, Sone T, Tanaka M, Yokota M: Prediction of the risk of myocardial infarction from polymorphisms in candidate genes. N Engl J Med, 2002; 347: 1916-1923

17) Fujiwara $S$, Emoto M, Komatsu M, Notoyama K, Morioka T, Koyama H, Shoji T, Inaba M, Nishizawa Y: Arterial wall thickness is associated with insulin resistance in type 2 diabetic patients. J Atheroscler Thromb, 2003; 10: $246-252$

18) Chambless LE, Heiss G, Folsom AR, Rosamond W, Szklo M, Sharrett AR, Clegg LX: Association of coronary heart disease incidence with carotid arterial wall thickness and major risk factors: The Atherosclerosis Risk in Communities:, ARIC; Study:, 1987-1993. Am J Epidemiol, 1997; 146: 483-494

19) Lee E, Emoto $M$, Teramura $M$, Tsuchikura $S$, Ueno $H$, Shinohara K, Morioka T, Mori K, Koyama H, Shoji T, Okuno Y, Inaba M, Nishizawa Y: The combination of IMT and stiffness parameter beta is highly associated with concurrent coronary artery disease in type 2 diabetes. J Atheroscler Thromb, 2009; 16: 33-39

20) O'Leary DH, Polak JF, Kronmal RA, Manolio TA, Burke GL, Wolfson Jr SK: Cardiovascular Health Study Collaborative Research Group: Carotid-artery intima and media thickness as a risk factor for myocardial infarction and stroke in older adults. N Engl J Med, 1999; 340: 14-22

21) Lusis AJ, Fogelman AM, Fonarow GC: Genetic basis of atherosclerosis: Part II Clinical Implications. Circulation, 2004; 110: 2066-2071

22) Frost D, Pfohl M, Clemens P, Haring HU, Beischer W: Evaluation of the insertion/deletion ACE gene polymorphism as a risk factor for carotid artery intima-media thickening and hypertension in young type 1 diabetic patients. Diabetes Care, 1998; 21: 836-840

23) Mannami $T$, Katsuya T, Baba $S$, Inamoto N, Ishikawa K, Higaki J, Ogihara T, Ogata J: Low potentiality of angiotensin-converting enzyme gene insertion/deletion polymorphism as a useful predictive marker for carotid atherogenesis in a large general population of a Japanese city: the Suita study. Stroke, 2001; 32: 1250-1256

24) Kogawa K, Nishizawa Y, Hosoi M, Kawagishi T, Maekawa K, Shoji T, Okuno Y, Morii H: Effect of polymorphism of apolipoprotein $\mathrm{E}$ and angiotensin-converting enzyme genes on arterial wall thickness. Diabetes, 1997; 46: 682687

25) Yamasaki Y, Tsujino T, Kodama M, Kajimoto Y: DD genotype of the ACE gene as an atherosclerosis-independent risk factor for myocardial infarction. Circulation, 1997; 96: 3782

26) Arai K, Yamasaki Y, Kajimoto Y, Watada H, Umayahara Y, Kodama M, Sakamoto K, Hori M: Association of methylenetetrahydrofolate reductase gene polymorphism with carotid arterial wall thickening and myocardial infarction risk in NIDDM. Diabetes, 1997; 46: 2102-2104

27) Yokoyama H, Katakami N, Yamasaki Y: Recent advances of intervention to inhibit progression of carotid intimamedia thickness in patients with type 2 diabetes mellitus. Stroke, 2006; 37: 2420-2427

28) Oyama T, Saiki A, Endoh K, Ban N, Nagayama D, Ohhira M, Koide N, Miyashita Y, Shirai K: Effect of acarbose, an alpha-glucosidase inhibitor, on serum lipoprotein lipase mass levels and common carotid artery intimamedia thickness in type 2 diabetes mellitus treated by sulfonyurea. J Atheroscler Thromb 2008; 15: 154-159

29) Rigat B, Hubert C, Alhenc-Gelas F, Cambien F, Corvol P, Soubrier F: An insertion/deletion polymorphism in angiotensin I-converting enzyme gene accounting for half the variance of serum enzyme levels. J Clin Invest, 1990; 86: 1343-1346

30) Toba H, Miki S, Shimizu T, Yoshimura A, Inoue R, Sawai N, Tsukamoto R, Murakami M, Morita Y, Nakayama Y, Kobara M, Nakata T: The direct antioxidative and antiinflammatory effects of peroxisome proliferator-activated receptors ligands are associated with the inhibition of angiotensin converting enzyme expression in streptozotocin-induced diabetic rat aorta. Eur J Pharmacol, 2006; 549: 124-132

31) Lawrence de Koning AB, Werstuck GH, Zhou J, Austin RC: Hyperhomocysteinemia and its role in the develop- 
ment of atherosclerosis. Clin Biochem, 2003; 36: 431-441

32) Robinson K, Mayer EL, Miller DP, Green R, Fvan Lente:, Gupta A, Kottke-Marchant K, Savon SR, Selhub J, Nissen SE, Kutner M, Topol EJ, Jacobsen DW: Hyperhomocysteinemia and low pyridoxal phosphate. Common and independent reversible risk factors for coronary artery disease. Circulation, 1995; 92: 2825-2830

33) Boushey CJ, Beresford SA, Omenn GS, Motulsky AG: A quantitative assessment of plasma homocysteine as a risk factor for vascular disease. Probable benefits of increasing folic acid intakes. JAMA, 1995; 274: 1049-1057

34) Christensen B, Frosst P, Lussier-Cacan S, Selhub J, Goy- ette P, Rosenblatt DS, Genest Jr J, Rosen R: Correlation of a common mutation in the methylenetetrahydrofolate reductase gene with plasma homocysteine in patients with premature coronary artery disease. Arterioscler Thromb Vasc Biol, 1997; 17: 569-573

35) Hsueh WA, Law RE: PPARgamma and atherosclerosis: effects on cell growth and movement. Arterioscler Thromb Vasc Biol, 2001; 21: 1891-1895

36) Blaschke F, Spanheimer R, Khan M, Law RE: Vascular effects of TZDs: new implicationsVascul Pharmacol, 2006; 45: 3-18 